\title{
Effect of Overexpression of PDAT Gene on Arabidopsis Growth Rate and Seed Oil Content
}

\author{
Walentyna Banaś ${ }^{1}$, Anders S. Carlsson ${ }^{2} \&$ Antoni Banaś $^{3}$ \\ ${ }^{1}$ Institute of Biology, University of Natural Sciences and Humanities, Siedlce, Poland \\ ${ }^{2}$ Department of Plant Breeding, SLU, Alnarp, Sweden \\ ${ }^{3}$ Intercollegiate Faculty of Biotechnology of UG and MUG, Gdańsk, Poland \\ Correspondence: Walentyna Banaś, Institute of Biology, University of Natural Sciences and Humanities, Prusa 12, \\ 08-110 Siedlce, Poland. Tel: 48-25-643-1203. E-mail: wbanas@uph.edu.pl
}

Received: February 7, 2014 Accepted: March 5, 2014 Online Published: April 15, 2014

doi:10.5539/jas.v6n5p65 URL: http://dx.doi.org/10.5539/jas.v6n5p65

\begin{abstract}
Arabidopsis (ecotype Columbia 0) plants was transformed with AtPDAT (phospholipid: diacylglycerol acyltransferase) gene behind the cauliflower mosaic virus 35S promoter. Transformed plants were selected by exposure to kanamycin and further grown on peat-based soil media in growth chamber. The seeds of T1 plants (T2 seeds) segregated and containing homozygotes, heterozygotes and null segregants (without transgene). The T3 seeds of selected null segregants and transformed homozygotes were further grown on peat-based soil media in growth chamber (T3 plants) and the lipid content in their seeds (T4 seeds) were evaluated. Additionally T4 seeds of selected null segregants and selected transformed plants (homozygotes) were used for evaluation of AtPDAT overexpression effect on seedlings growth rate, measurement of PDAT activity and for greenhouse experiments. Results show that PDAT overexpression increased the growth rate of Arabidopsis plants. This phenomenon was observed both during germination and further growth of the seedlings on agar plate as well as during the germination and further growth of the plant on peat-based soil media during the greenhouse experiment. The positive effect on oil production in transformed plants was also observed, however, it was probably not directly attributable to PDAT action but rather an indirect cause of growth stimulation.
\end{abstract}

Keywords: Arabidopsis, phospholipid, diacylglycerol acyltransferase, lipids, triacylglycerol, growth rate

\section{Introduction}

PDAT (phospholipid : diacylglycerol acyltransferase) is an enzyme participating in the last step of triacylglycerol (TAG) synthesis in yeasts and plants (Banaś et al., 2000; Dahlqvist et al., 2000; Oelkers et al., 2000; Stål et al., 2004). TAG despite being the main storage compound of majority of seeds, constitutes only a minor fraction of all lipids in vegetative tissues (Stymne \& Stobart, 1987; Ståhl et al., 2004; Głąb et al., 2013; Fan et al., 2013a, 2013b; Vanhercke et al., 2014). TAG biosynthesis occurs in endoplasmic reticulum (ER) via sequential acylation of the glycerol backbone. In majority of seeds TAG is accumulated in oil bodies generated through budding off from the outer ER membrane (Stymne \& Stobart, 1987; Ohlrogge \& Browse, 1995; Huang, 1996; Chapman et al., 2012). Neither accumulation nor the role of TAG in vegetative tissues (leaves, roots) has been well characterized. Enzymes of DGAT type (acyl-CoA:diacylglycerol acyltransferase) are involved besides PDAT, in the last step of triacylglycerol biosynthesis (Kennedy, 1961; Stymne \& Stobart, 1987; Ohlrogge \& Browse, 1995; Cases et al., 1998; Zhu et al., 1999; Hobbs et al., 1999; Bouvier-Nave et al., 2000; Lardizabal et al., 2001; Kroon et al., 2006; Shockey et al., 2006; Zhang et al., 2009; Saha et al., 2006; Liu et al., 2012; Hernandez et al., 2012). Until the discovery of PDAT (Dahlqvist et al., 2000; Oelkers et al., 2000) it was commonly believed that DGAT was the only enzyme involved in TAG biosynthesis and some of the performed experiments suggested that it may catalyze a rate-limiting reaction in TAG bioassembly (Perry \& Harwood, 1993a, 1993b; Settlage et al., 1995; Perry et al., 1999). It was also shown, that over-expression of DGAT gene in wild-type of Arabidopsis was positively correlated with an increase in oil accumulation and average seed weight (Jako et al., 2001).

After the discovery of PDAT (Dahlqvist et al., 2000; Oelkers et al., 2000), scientists had pinned hopes on its overexpression will increase the synthesis and accumulation of TAG in seeds of oilseed plants. Early results 
obtained with yeast (Saccharomyces cerevisiae) strengthened these expectations. The overexpression of PDAT increased TAG accumulation in yeast cells by up to $150 \%$ of control value (Dahlqvist et al., 2000). Nevertheless, the first results with PDAT overexpressed Arabidopsis plants were disappointing, suggesting only negligible impact on lipid content and composition (Ståhl et al., 2004). The results presented in this paper form a continuation of the above mentioned experiments. The number of studied overexpressors and control plants was extended. Besides the effects on lipid content and composition also impact of PDAT overespression on plant growth was investigated. Results show that PDAT overexpression increased the growth rate of Arabidopsis plants. Moreover an increase in oil production by transformed plants was also observed. However, it was probably not a direct PDAT action but rather an indirect cause of growth stimulation.

\section{Materials and Methods}

\subsection{Transformation and Selection of Homozygotes and Null Segregants}

The transformation method of Arabidopsis (ecotype Columbia 0) plants with PDAT gene was described earlier (Ståhl et al., 2004). The seeds of transformed plants were germinated on Petri dishes, containing one-third $(1.4 \mathrm{~g} / \mathrm{L})$ Murashige and Skoog medium with $1 \%$ sucrose and kanamycin $(50 \mu \mathrm{g} / \mathrm{ml})$ solidified by agar $(0.7 \%)$, at $20^{\circ} \mathrm{C}$ under light. The germinated seeds were treated as transformed with PDAT (T1 seeds; heterozygote). 10-day-old seedlings (T1 plants; heterozygote) were transferred to peat-based soil media and grown further in growth chamber with $70 \%$ humidity and $16 \mathrm{~h}$ light $\left(200 \mu \mathrm{mol}\right.$ radiation $\left.\mathrm{m}^{-2} \mathrm{~s}^{-1}\right)$. Individual seeds (the seeds of T1 plants -T2 seedssegregated and contained homozygotes, heterozygotes and null segregants - without transgene) of T1 plants were germinated and grown on peat-based soil media in the growth chamber (T2 plants). The seeds (T3 seeds) were germinated on agar plates containing kanamycin (growth condition and medium composition described above) and plants whose all seeds germinated were treated as homozygotes, with partial seeds germination (about $75 \%$ ) as heterozygotes and with no germinated seeds as null segregants (Supplement, Photo S1). In the presented study progeny of three transformed plants (T1 plants) identified by the numbers: "1", "2" and "3b", were used.

\subsection{The Effect of PDAT Overespression on Lipid Content in Seeds}

The T3 seeds from Arabidopsis plants which proved to be homozygotes and null segregants were further germinated and cultivated on peat-based soil media $(0.5 \mathrm{~L} /$ pot; 1 plant/pot) in growth chamber (conditions described above). In total 24 null segregants (T3 plants; 7 progeny of " 1 ", 7 progeny of "2", and 10 progeny of " $3 \mathrm{~b}$ ") and 32 homozygotes (T3 plants; 9 progeny of " 1 ", 11 progeny of "2" and 12 progeny of " $3 \mathrm{~b}$ ") were investigated for effects of PDAT overexpression on lipid content in seeds. After desiccation the seeds (T4 seeds) were harvested and used for lipid content analyses.

\subsection{The Effect of PDAT Overexpression on Arabidopsis Seedlings Growth}

In the preliminary experiments the seeds of overexpressor "D1-1-6" (T3 seeds) were used for the study. This homozygote was chosen for the experiments because it has been proven by Northern analyses to contain a very high PDAT gene expression (Ståhl et al., 2004). The seeds of "D1-1-6" overexpressor and the control seeds were germinated on Petri dishes, containing one-third (1.4 g/ L) Murashige and Skoog medium with $1 \%$ sucrose solidified by agar $(0.7 \%)$ at $23^{\circ} \mathrm{C}$ under constant light. After 17 days the seedlings were weighted and used for lipid content analysis.

The following experiments were performed on $\mathrm{T} 4$ seeds from T3 plants, used for the evaluation of the effect of PDAT overexpression on lipid content in Arabidopsis seeds. In total, the seeds from 22 null segregants and 30 homozygotes were studied. The seeds were germinated on agar plate (conditions as above) and after 19 days (Supplement, Photo S2) were analysed as described above for overexpressor "D1-1-6" seedlings.

All experiments were repeated at least 3 times with 25-30 seeds/Petri dish.

\subsection{The Greenhouse Experiment}

The T4 seeds of overexpressors with the highest seedlings growth rate (section above) were selected for greenhouse experiments. The selection was additionally supported by analyses of PDAT activity in the leaves of seedlings bred from these seeds (see section below). The seeds of selected overexpressors and null segregants were germinated on peat-based soil media and cultivated from March to May (control plants about 80 days and the transformed ones a few days longer; the desiccation started later) in greenhouse under controlled growth conditions (Supplement, Photo S5). Three pots (containing 3L of peat-based soil media each) were used for germination and development of each individual control or PDAT overexpressed plants (after germination 3 plants/pot were left for further growth). After desiccation, the seeds and aerial parts of Arabidopsis plants from each pot were harvested separately and analysed further. The aerial parts of the analysed plants were dried for 
48-hrs at $80^{\circ} \mathrm{C}$ and then weighted. The seeds (aerial dry) from each pot were first weighted and then used for lipid content analyses.

\subsection{PDAT Activity in the Leaves of Selected Overexpressors}

$\mathrm{T} 4$ seeds of selected overexpressors and null segregants were germinated on agar plate (condition described earlier) and after 14 days transferred into beakers ( 3 seedlings/ beaker) with $100 \mathrm{ml}$ of liquid medium (containing one-half Murashige and Skoog medium with $1 \%$ sucrose) and subject to gentle shaking ( $80 \mathrm{rpm}$ ) during further growth for additional 21 days under constant light $\left(80 \mu \mathrm{mol}\right.$ radiation $\left.\mathrm{m}^{-2} \mathrm{~s}^{-1}\right)$. After that time, microsomal membranes from leaves were prepared according to the method described by Stobart \& Stymne (1985). Aliquots of crude microsomal fractions (corresponding to $12 \mathrm{nmol}$ of microsomal PC; approximately $53 \mu \mathrm{g}$ protein) were lyophilized overnight. Substrates (2.5 nmol of sn-1-18:1- sn-2[14C]18:2-PE and 1.5 of di-18:1-DAG) dissolved in $19 \mu \mathrm{l}$ of benzene were added to the dry microsomes, while benzene was evaporated immediately under nitrogen. Afterwards $0.1 \mathrm{ml}$ of $0.1 \mathrm{M}$ potassium phosphate buffer $(\mathrm{pH} 7.2)$ was added and the suspensions were intensively mixed (1250 rpm) for $60 \mathrm{~min}$ at $30^{\circ} \mathrm{C}$. Lipids were extracted from the reaction mixture to chloroform (Bligh \& Dyer, 1959) and separated on TLC with hexane/diethyl ether/acetic acid (70:30:1 by volume) using silica gel plates (Merck, Darmstadt, Germany). The radioactive lipids were visualized and quantified on the plates using electronic autoradiography (Instant Imager, Packard Instruments).

All assays were repeated at least three times.

\subsection{Lipid Analyses}

Plant material (except the seeds) was homogenized in chloro form: methanol: $0.15 \mathrm{M}$ acetic acid $(1: 2: 0.8)$ using a Potter Elvehjem homogenizer. The lipids were subsequently extracted into chloroform according to Bligh and Dyer (1959). For total lipids analysis, aliquots of the chloroform phase were evaporated and methylated as described below. Individual lipids in the chloroform phase were separated by TLC in hexane:diethyl ether:acetic acid $(70: 30: 1)$ in case of neutral lipids or in chloroform:methanol:aceticacid:water ( $85: 15: 10: 3.5)$ for separation of polar lipids. Gel, from areas corresponding to the analysed lipid classes (identified by means of standards), was removed and lipids were methylated in situ on the gel with $2 \% \mathrm{H}_{2} \mathrm{SO}_{4}$ in dry methanol $\left(60 \mathrm{~min}\right.$ at $\left.90^{\circ} \mathrm{C}\right)$. Seed lipids were methylated without prior extraction into chloroform. Portions of 3 to $5 \mathrm{mg}$ of aerial dry seeds (3-6 replications/ analysed plant) were incubated for $90 \mathrm{~min}$ at $90^{\circ} \mathrm{C}$ with $3 \mathrm{ml}$ of $2 \% \mathrm{H}_{2} \mathrm{SO}_{4}$ in dry methanol. The methyl esters were extracted with hexane and analysed by GLC equipped with a flame ionization detector and a WCOT fused-silica $50 \mathrm{~m} \times 0.32 \mathrm{~mm}$ ID coating CP-Wax 58-CB DF 50.2 capillary column (Chrompack International, Middleburg, The Netherlands) with methyl-heptadecanoic acid added as an internal standard.

\section{Results}

In the preliminary experiments we have shown that direct methylation of Arabidopsis seed lipids, without prior lipid extraction, could be satisfactorily used for evaluation of lipid content in the seeds (data not presented). The lipid amount (measured as a sum of total lipids' fatty acids) estimated by both methods (prior extraction of the lipids into chloroform or direct methylation; see Material and Methods) produced very similar values. Thus, in the presented study we decided to use the "direct methylation of seed lipids" method as it was faster, and as accurate as the traditional methods with prior extraction of lipids (Bligh \& Dyer, 1959).

For evaluation of PDAT overexpression on lipid content in Arabidopsis seeds, 23 "null segregants" and 31 "PDAT overexpressor" were examined. The lipid content in the seeds (expressed as total fatty acid content in seed lipids) of different plants varied substantially. In "null segregants" from 1223 to $1424 \mathrm{nmol} \mathrm{FA}$ / mg seeds and in transformed plants (homozygotes) from 1217 to $1472 \mathrm{nmol} \mathrm{FA} / \mathrm{mg}$ seeds (Figure 1 and 2). The average lipid content in seeds of control plants (null segregants - the lines without transgene) was similar to the average lipid content in seeds of transformed (homozygous) plants (1335 \pm 56 and $1336 \pm 56 \mathrm{nmol} \mathrm{FA} / \mathrm{mg}$ seeds respectively). In the control plants the majority of progeny of transformant " $3 \mathrm{~b}$ " were slightly above and of progeny of transformants "1" and "2" a bit below the average value (Figure 1). In the transformed plants such a tendency was not observed. To the contrary, in the progeny of transformant " $3 \mathrm{~b}$ " the highest percentage of plants with seeds' lipid content below the average value was observed. There were two plants with oil content in the seeds significantly higher than in control - one amongst the progeny of transformant " 1 " (plant $6 \mathrm{H}$ ) and one amongst the progeny of transformant " $3 \mathrm{~b}$ " (plant $31 \mathrm{H}$ ). However, in both cases the increase was only about $10 \%$ over the average control values and only about $3 \%$ higher than the highest oil content values in control plants. The fatty acid composition of seed lipids of both control and transformed plants was very similar (data not shown). 


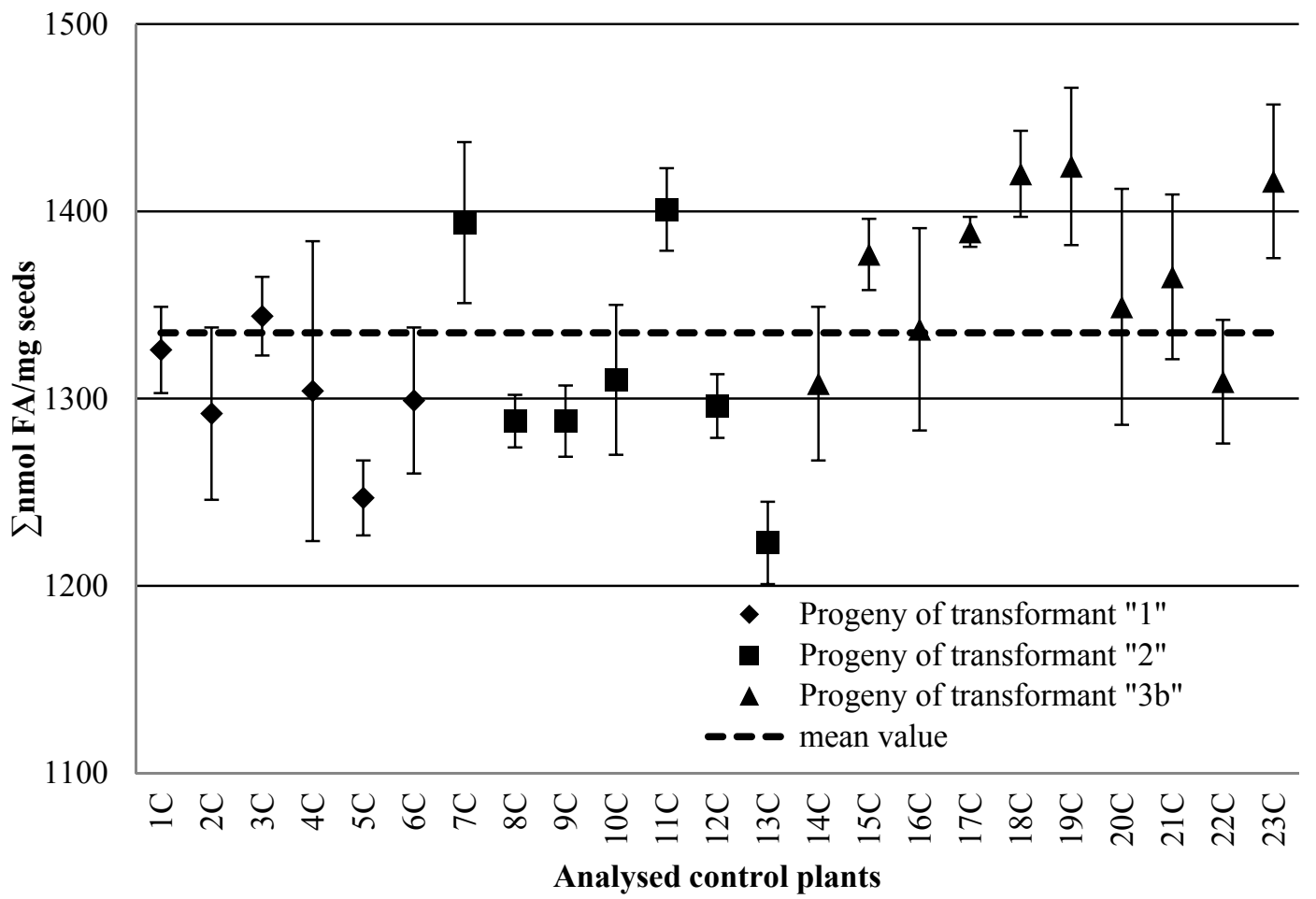

Figure 1. Lipid content (presented as a sum of lipids' fatty acids) in seeds of "null segregants" (control lines; without transgene); progeny of Arabidopsis plants transformed with PDAT gene (T4 seeds) grown in the biotron.

The dotted line shows the average lipid content in seeds of analyzed plants

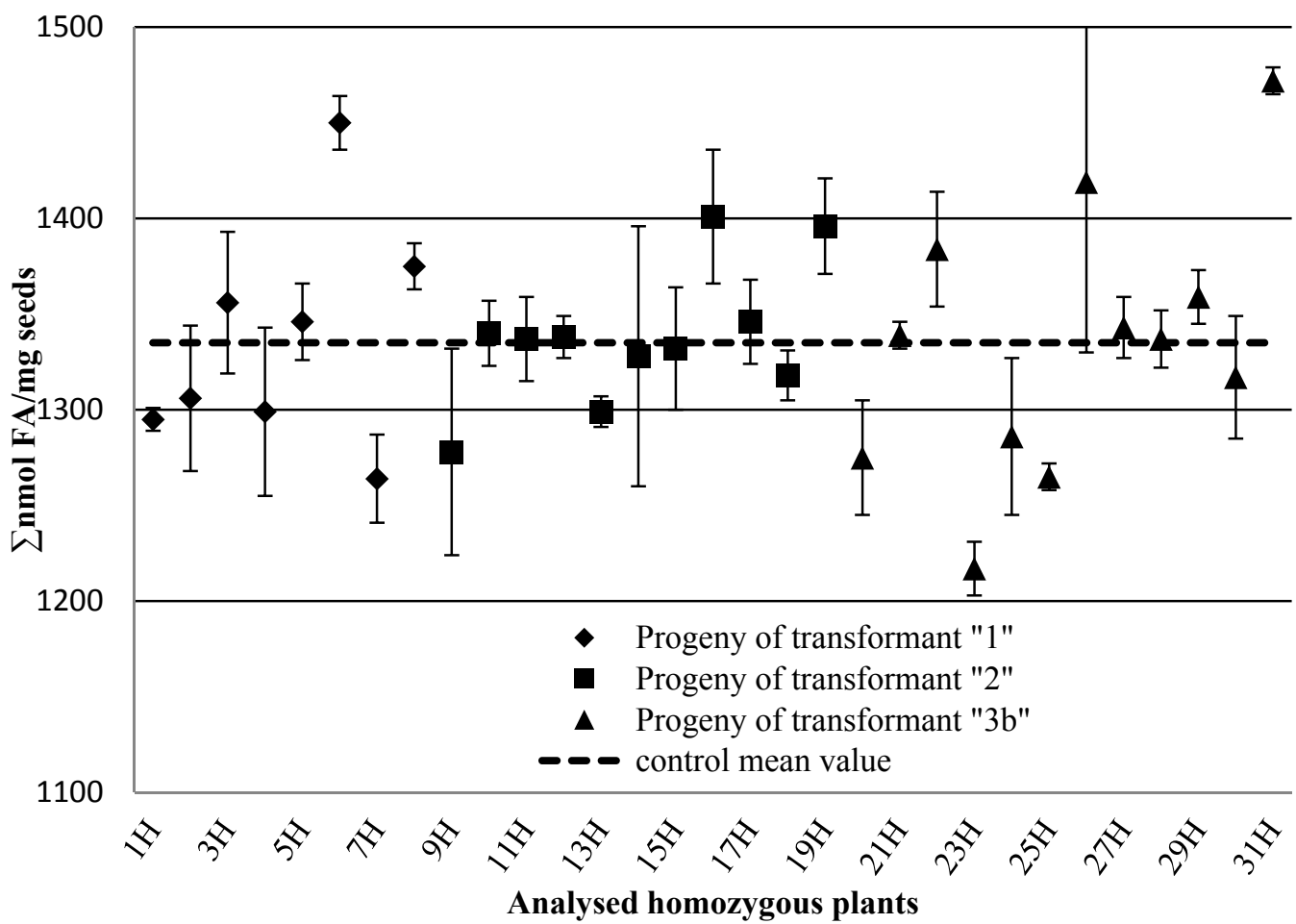

Figure 2. Lipid content (presented as a sum of lipids' fatty acids) in seeds of Arabidopsis plants transformed with PDAT gene (homozygous plants; T4 seeds) grown in the biotron. The dotted line shows the average lipid content in seeds of analyzed plants 
In the preliminary investigation of the effects of PDAT overexpression on Arabidopisis growth, the seeds of transformant "D1-1-6" showing a very high expression of PDAT gene (Ståhl et al., 2004), were used. It was observed, that the seeds of transformed plants germinated a bit faster and the seedlings growth rate was also higher than in case of control. After 17 days on agar plate the fresh weight of transformed seedlings was more than $50 \%$ higher than the control. The higher weight of transformed plants was well correlated with the amount of lipids/seedling, showing that the increase in weight is not simply resulting from higher water content. However, when the amount of lipids (presented as a sum of lipids' fatty acids) was calculated per mg of fresh weight, the lipid content in transformed and control seedlings was almost the same (Table 1).

Table 1. Effect of overexpression of PDAT gene (T3 plants) on growth (17 days on agar plate) of Arabidopsis seedlings

\begin{tabular}{|c|c|c|c|c|c|c|}
\hline \multirow{2}{*}{ Plant } & \multicolumn{2}{|c|}{ Fresh weight/ 1 seedling } & \multicolumn{2}{|c|}{ इnmol FA/1 seedling } & \multicolumn{2}{|c|}{$\Sigma \mathrm{nmol} \mathrm{FA} / \mathrm{mg}$ fresh weight } \\
\hline & $\mathrm{mg}$ & $\% \mathrm{C}$ & nmol & $\% \mathrm{C}$ & nmol & $\% \mathrm{C}$ \\
\hline Control & $7.3 \pm 0.9$ & 100 & $93.6 \pm 7.7$ & 100 & $12.8 \pm 1.0$ & 100 \\
\hline Transformed plant - D1-1-6 & $11.3^{\mathrm{a}} \pm 1.8$ & 155 & $141.3^{\mathrm{a}} \pm 0.3$ & 151 & $12.9 \pm 2.3$ & 101 \\
\hline
\end{tabular}

Mean \pm S.D. shown; a - significant difference between control and transformed plants in mean difference two-sided test at $\alpha=0.05$.

To confirm that observed elevated growth rate of seedlings of tested overexpressor is not a one-off event not necessarily caused by PDAT overexpression, we extended the number of studied plants. For the experiments we used 22 "null segregants" and 31 transformed (homozygous) plants (T4 plants; the same seeds as used for lipid content analyses - Figures 1 and 2 - were used for germination). The average weight of seedlings of "null segregants" ranged from 9.6 to $11.9 \mathrm{mg}$ / seedling and most of them were close to the average values from all 22 "null segregants" (Figure 3). The average weight of seedlings of tested homozygous plants ranged from 10.1 to $15.5 \mathrm{mg} /$ seedling (Figure 4). The average values of seedlings of 18 tested homozygous plants was higher than the highest average values of tested "null segregants". The next 8 had higher weight than average value of all "null segregants" and seedlings of 4 remaining homozygotes had average weight similar to the average values of control Only seedlings of one of the tested homozygotes had average weight a bit lower than the average weight of control seedlings (Figure 4). The expression levels of PDAT gene in "null segregants" (control) and transformed (homozygous) plants were not analysed. However, judging from the evaluation of PDAT activity in selected control and transformed plants (description below), at least the homozygotes with the highest growth rate had higher PDAT activity than the control plants. 


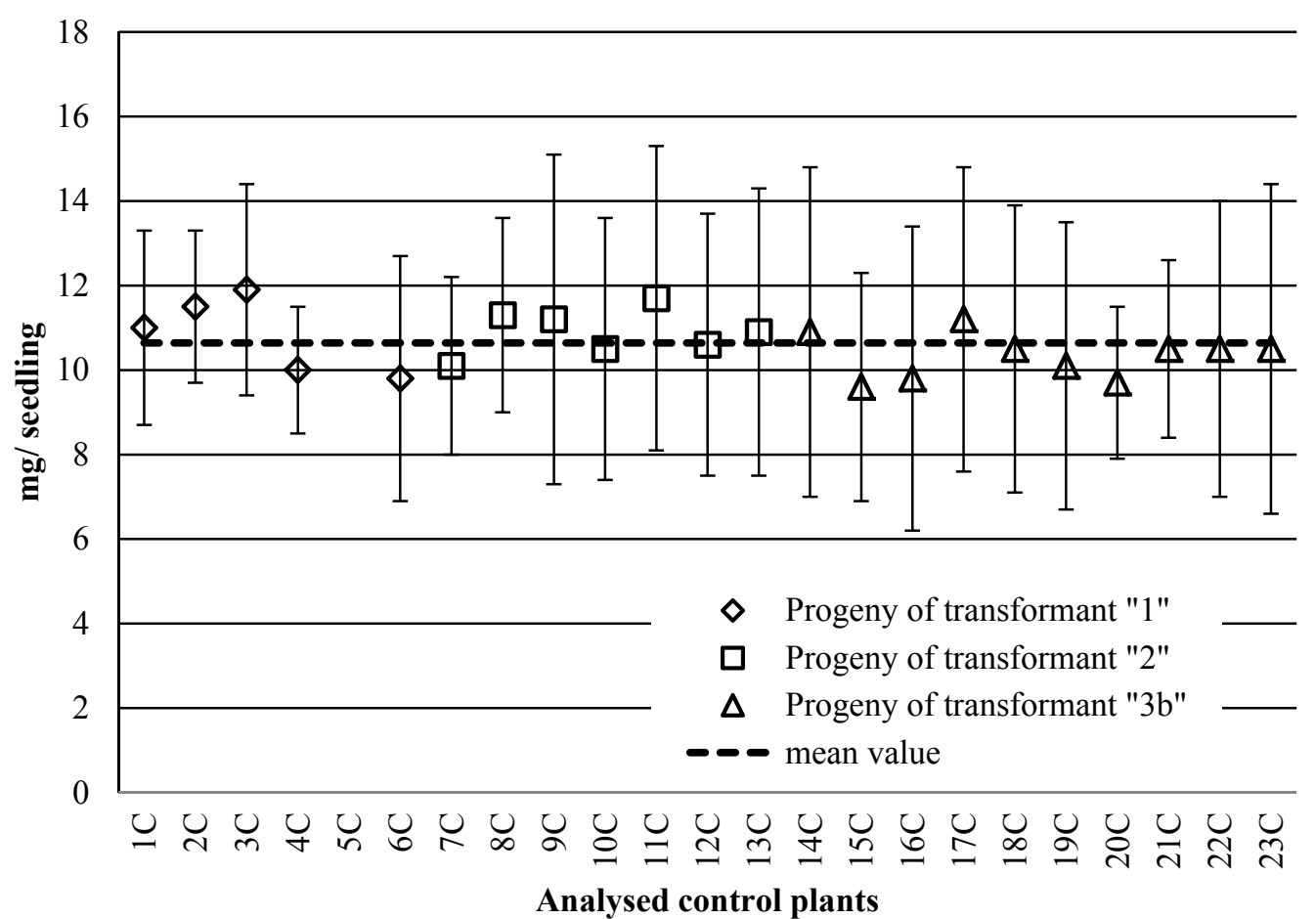

Figure 3. Fresh weight of "null segregants" (control lines; without transgene) seedlings (T4 plants) grown on agar plate for 19 days; progeny of Arabidopsis plants transformed with PDAT gene. The dotted line shows the average weight of seedling of analyzed plants

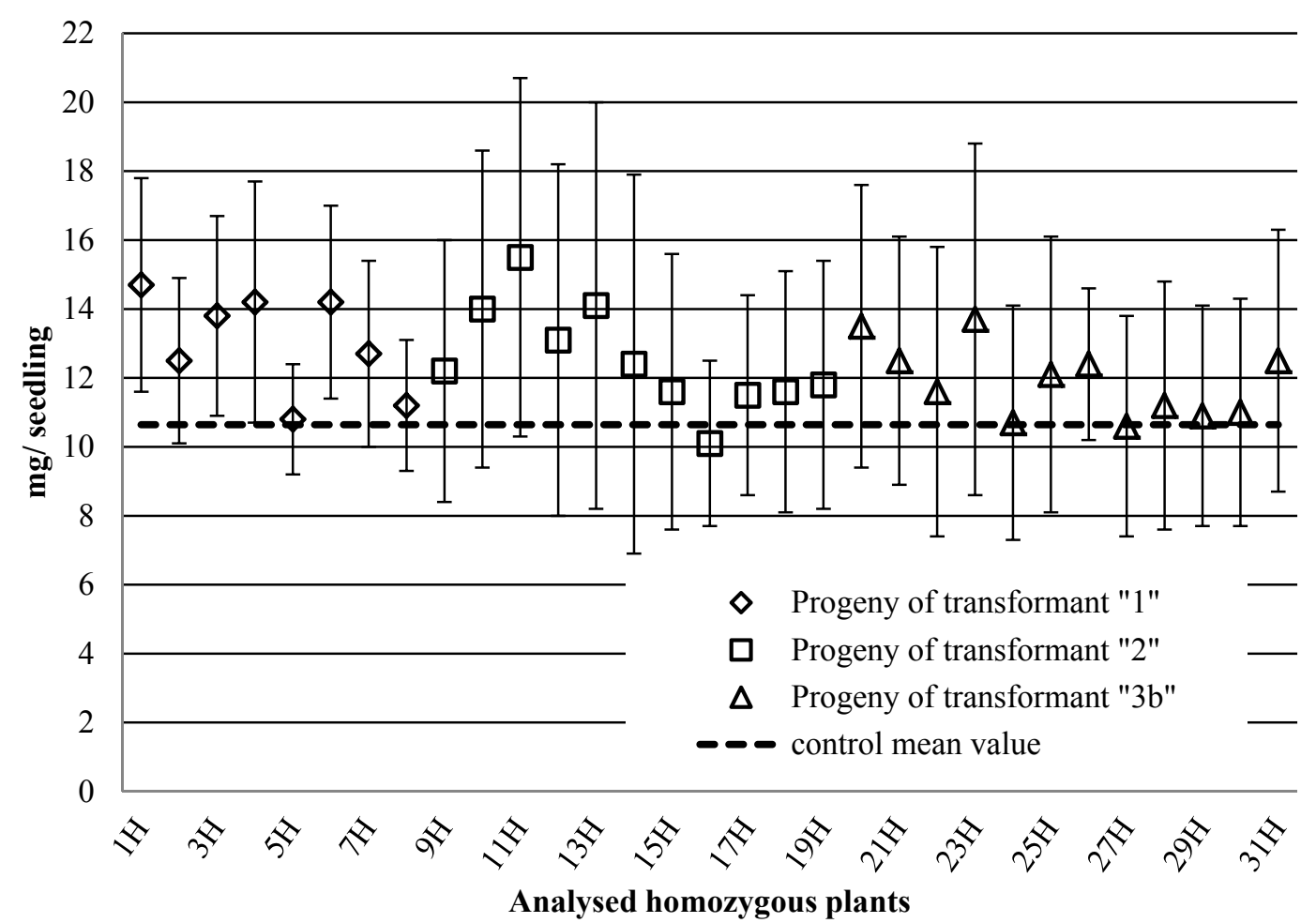

Figure 4. Fresh weight of Arabidopsis seedlings overexpressed with PDAT gene (T4 plants; homozygotes) grown on agar plate for 19 days. The dotted line shows the average weight of seedling of control plants (see Figure 3 ) 
Similarly to the experiments with "D1-1-6" overexpressor discussed above, the increase in seedlings weight of majority of other tested overexpressors compared to the weight of control seedlings was well correlated with the increase in lipid content per seedling (data not presented). Also the average lipid content/ $\mathrm{mg}$ of fresh weight and fatty acid composition of lipids of the control and PDAT overexpressors were nearly the same (Table 2).

Table 2. Effect of overexpression of PDAT gene (T4 plants) on fatty acid composition of lipids of Arabidopsis seedlings

\begin{tabular}{|c|c|c|c|c|c|c|c|c|}
\hline \multirow{2}{*}{ Plant } & \multirow{2}{*}{$\begin{array}{l}\sum \text { nmol FA } / \mathrm{mg} \\
\text { fresh weight }\end{array}$} & \multicolumn{7}{|c|}{ Fatty acids [Mol \%] } \\
\hline & & $16: 0$ & $16: 3$ & $18: 0$ & $18: 1$ & $18: 2$ & $18: 3$ & others \\
\hline Controls $(\mathrm{n}=22)$ & $11.0 \pm 0.9$ & $12.2 \pm 0.6$ & $16.0 \pm 0.5$ & $1.1 \pm 0.1$ & $1.4 \pm 0.2$ & $16.7 \pm 0.6$ & $50.0 \pm 1.2$ & $2.6 \pm 0.3$ \\
\hline Transfomants $(n=31)$ & $11.1 \pm 0.8$ & $12.2 \pm 0.5$ & $16.1 \pm 0.4$ & $1.1 \pm 0.2$ & $1.2^{\mathrm{a}} \pm 0.2$ & $16.6 \pm 1.4$ & $50.4^{\mathrm{a}} \pm 1.0$ & $2.4 \pm 0.2$ \\
\hline
\end{tabular}

Average values \pm S.D. shown; Controls $=$ "null segregants", Transformants $=$ homozygous plant (for analyses the same seedlings as indicated in Figures 3 \& 4 were used).

a - significant difference between control and transformed plants in mean difference two-sided test at $\alpha=0.05$.

Table 3. Effect of overexpression of PDAT gene (T4 plants) on: dry weight of aerial parts, the amount of produced seeds and lipid content in seeds of Arabidopsis plants gown for about 80 days in greenhouse

\begin{tabular}{llllll}
\hline Plant & $\begin{array}{l}\text { PDAT activity } \\
\text { [pmol TAG/ min x mg } \\
\text { protein] }\end{array}$ & $\begin{array}{l}\text { Dry weight/3 } \\
\text { plants } \\
{[\mathrm{g}]}\end{array}$ & $\begin{array}{l}\text { Seeds/3 } \\
\text { plants } \\
{[\mathrm{g}]}\end{array}$ & $\begin{array}{l}\text { nmol FA / mg } \\
\text { seeds }\end{array}$ & $\begin{array}{l}\mu \mathrm{mol} \text { FA/3 } \\
\text { plants }\end{array}$ \\
\hline $2 \mathrm{C}$ & 1.4 & $3.89(98)$ & $2.14(100)$ & $1228(101)$ & $2628(101)$ \\
$4 \mathrm{C}$ & 2.2 & $3.96(100)$ & $2.13(99)$ & $1167(96)$ & $2475(95)$ \\
$14 \mathrm{C}$ & 1.9 & $4.04(102)$ & $2.15(101)$ & $1250(103)$ & $2688(104)$ \\
$\mathrm{C}$ & 1.9 & $3.96(100)$ & $2.14(100)$ & $1213(100)$ & $2597(100)$ \\
average & & & & & \\
value & & & & & $3306(127)$ \\
\hline $1 \mathrm{H}$ & $18.6^{\mathrm{a}}$ & $4.66^{\mathrm{a}}(118)$ & $2.62^{\mathrm{a}}(122)$ & $1226(104)$ & $3080(119)$ \\
$3 \mathrm{H}$ & $6.8^{\mathrm{a}}$ & $4.39(111)$ & $2.48^{\mathrm{a}}(116)$ & $1242(102)$ & $2845(110)$ \\
$4 \mathrm{H}$ & $3.3^{\mathrm{a}}$ & $4.32(109)$ & $2.33(109)$ & $1221(101)$ & $2666(103)$ \\
$6 \mathrm{H}$ & $5.1^{\mathrm{a}}$ & $4.38(111)$ & $2.22(104)$ & $1201(99)$ & $3387(130)$ \\
$10 \mathrm{H}$ & $16.7^{\mathrm{a}}$ & $4.88^{\mathrm{a}}(123)$ & $2.63^{\mathrm{a}}(123)$ & $1288^{\mathrm{a}}(106)$ & $3289(127)$ \\
$11 \mathrm{H}$ & $8.4^{\mathrm{a}}$ & $4.67^{\mathrm{a}}(118)$ & $2.53^{\mathrm{a}}(118)$ & $1300^{\mathrm{a}}(107)$ & $3238(125)$ \\
$13 \mathrm{H}$ & $4.7^{\mathrm{a}}$ & $4.58^{\mathrm{a}}(116)$ & $2.51^{\mathrm{a}}(117)$ & $1290^{\mathrm{a}}(106)$ & $3351(129)$ \\
$23 \mathrm{H}$ & $6.8^{\mathrm{a}}$ & $4.52^{\mathrm{a}}(114)$ & $2.56^{\mathrm{a}}(120)$ & $1309^{\mathrm{a}}(108)$ & $2827(109)$ \\
$31 \mathrm{H}$ & $9.5^{\mathrm{a}}$ & $4.24(107)$ & $2.24(105)$ & $1247(103)$ & $3109^{\mathrm{a}}(120)$ \\
$\mathrm{H}$ & $8.9^{\mathrm{a}}$ & $4.48^{\mathrm{a}}(114)$ & $2.43^{\mathrm{a}}(114)$ & $1262(104)$ & \\
average & & & & & \\
value & & & & & \\
\hline
\end{tabular}

Mean values shown; average S.D.: $36 \%, 6 \%, 6 \%$ and 5\% of mean value for PDAT activity, dry weight of plant, seed amount and nmol FA / mg seeds, respectively; in brackets \% of average control value; a - significant difference between control and transformed plants in mean difference two-sided test at $\alpha=0,05$; PDAT activity was evaluated in microsomal preparations from leaves (T4 plants) of plants grown in liquid culture; average seeds amount and fatty acid content in mg seeds were used for calculation of $\mu \mathrm{mol} \mathrm{FA} / 3$ plant.

For evaluation of the overall effect of PDAT overexpression on Arabidopsis growth, greenhouse experiments were conducted. In our opinion the conditions in greenhouse are closer to naturally existing than those in biotron. 
Moreover, use of a greenhouse also eliminates to a great extent problems with space which are inherent to biotron conditions. For greenhouse experiment 3 control plants were selected $(2 \mathrm{C}$ with seedlings growth rate a bit higher, $4 \mathrm{C}$ with seedlings growth rate a bit lower and $14 \mathrm{C}$ with seedlings growth rate the same as average growth rate of all tested null segregants; Figure 3). From transformed plants, 9 homozygotes, with the highest seedlings growth rate (experiments with germination on agar plate; Figure 4.) were chosen (the $31 \mathrm{H}$ transformant was chosen because in biotron experiment the seeds of this homozygote had the highest seeds lipid content; Figure 2). The PDAT activity in the selected lines was measured in leaves of plants grown in liquid culture. In our earlier experiments we have shown that this type of plant material is the most appropriate for studying PDAT activity since its measurements are well correlated with PDAT gene expression (Ståhl et al., 2004). All the tested homozygous plants had significantly higher PDAT activity than the control, however the level of PDAT activity in analysed homozygotes differed considerably (Table 3). The highest PDAT activity level was detected in leaves of $1 \mathrm{H}$ and $10 \mathrm{H}$ transformants and the lowest in $4 \mathrm{H}$ (Table 3). The seeds (T4 seeds) from the same plants as used for PDAT activity study were applied in the greenhouse experiments, thus we were expecting that PDAT activity in the plants grown in the greenhouse will, to a certain degree, be correlated with PDAT activity measured in leaves of the plants grown in liquid culture.

Control and transformed plants were growing in the greenhouse for about 80 days until natural desiccation and were analysed afterwards. Each of three control plants used in experiments was cultivated in different place of the greenhouse; however this had not affected the size of plants nor the amount of produced seeds. The dry weight of all three control plants and the amount of produced seeds was similar. Thus we can conclude that the environmental condition in different places of greenhouse do not affected the plant growth rate.

The seeds of PDAT overexpressed plants germinated faster and the growth rate of seedlings was higher than the control ones (Supplement, Photo S4 \& S5). All analysed homozygous plants were bigger than the control plants (Supplement, Photo S6). The dry weight of aerial parts of the plants was higher than the control (107 to $123 \%$ of control average dry weight) as was the amount of produced seeds (105 to $123 \%$ of control average value). While the plants with the highest PDAT activity $(10 \mathrm{H}$ and $1 \mathrm{H}$ homozygotes) were also characterised by the highest growth rate (dry weight of plants, the amount of produced seeds), there was no absolutely strict correlation between PDAT activity and the growth rate of the other tested homozygotes (Table 3). The amount of the lipid content in seeds (nmol FA / mg seeds) was in most tested homozygotes similar or only a bit higher than the amount of lipid content in the seeds of control plants (from 101 to $108 \%$ of average control values). Nevertheless, the total amount of lipids produced by transformed plants was significantly higher than produced by control ones due to increased amounts of produced seeds. On average it was $120 \%$ of average control value, and for transformants with highest PDAT activity: $1 \mathrm{H}$ and $10 \mathrm{H}$, it was respectively about 127 and $130 \%$ of average control value of produced oil per plant (Table 3).

\section{Discussion}

The presented study contradicts expectations that PDAT overexpression will increase the TAG accumulation in seeds of oilseeds plants. However, it also provides a glimmer of hope. The total production of oil per plant in all of the studied PDAT overexpression in greenhouse experiments was higher than in studied control plants. The higher oil production was mostly a result of a higher amount of seeds produced by PDAT overexpressors, while this phenomenon was most probably connected with the elevated growth of transformed plants. The increase in plant growth was a completely unexpected effect of PDAT transformation. For instance it was neither reported in Arabidopsis plants overexpressed with DGAT gene (Jakko et al., 2001) nor with PDAT (Fan et al., 2013a, 2013b). In Arabidopsis, the PDAT gene is expressed not only in seeds, but also in roots, leaves and flowers (Ståhl et al., 2004). Thus, it can be expected that it plays a role not only in seed oil biosynthesis. As fatty acid donors for PDAT activity serve phospholipids and especially phosphatidylethanolamine and phosphatidylcholine with polyunsaturated or oxygenated fatty acids in sn-2 position (Banaś et al., 2000; Dahlqvist et al., 2000; Ståhl et al., 2004, Banaś et al., 2013). Therefore, elevated PDAT activity in vegetative tissues will trigger higher turnover of phospholipids and purification of membrane lipids from oxygenated fatty acids. In turn it could be expected that this will protect membranes from the negative impacts of oxidative stress on plant development, which at least partially could explain the elevated growth of PDAT overexpressed plants. In spite of elevated PDAT activity, we did not see an increase in TAG accumulation in leaves of PDAT overexpressed Arabidopsis plants (Ståhl et al., 2004; data not presented). This stays in contrast with parallel studies (Fan et al., 2013a, 2013b) which shown a clear increase of TAG content in leaves of PDAT overexpressed Arabidopsis plants. Perhaps, the stage of development, ecotype of used Arabidopsis plants or the level of PDAT activity in the transformed plants, or all of these factors together produced such different results. In our experiments we used for analyses of lipid composition of leaves of 17-19 days old seedling, grown on agar while Fan et al. (2013a, 2013b) investigated leaves of 
somewhat older plants grown in soil. We used ecotype Colombia 0, while Fan et al. (2013a, 2013b) used Colombia 2. The PDAT activity cannot be compared as in both experiments different methods were used for evaluation of PDAT gene expression. Both our and Fan et al. (2013a, 2013b) experiments suggest that PDAT overexpression stimulates fatty acid synthesis in leaves of transformed plants. In our experiments it was connected with an increased membrane lipids synthesis in faster developing cells (increased rate of plant growth was well correlated with the increased amount of lipids/seedling), while in Fan et al. (2013a, 2013b) research, with increased TAG synthesis. One can also consider that in the case of our experiments synthesized TAG was quickly mobilized. Kelly et al. (2013) showed for instance that after the knock-out of Arabidopsis TAG lipases, an elevated level of TAG was accumulating in leaves.

The expected elevated level of TAG in seeds of PDAT overexpressed plants was only occasionally observed. During the biotron experiments only 2 of PDAT overexpressor $(6 \mathrm{H}$ and $31 \mathrm{H})$ had significantly higher oil content than control plants as had 4 out of 9 tested overexpressors during greenhouse experiments. However, the observed increase in oil content does not seem to be directly connected with PDAT activity. The transformants $6 \mathrm{H}$ and $31 \mathrm{H}$ did not have elevated oil content in seeds during the greenhouse experiments, and in transformant $1 \mathrm{H}$ with the highest PDAT activity, the lipid content in seeds did not statistically differ from the oil content in the control plants neither in the biotron nor in greenhouse experiments. Thus, we conclude that observed differences in oil content in seeds of Arabidopsis plants are natural variations in oil content rather than the effect of PDAT overexpression. Moreover, the conditions of plant growth influence substantially the oil content. For instance, in the "biotron" experiments, the average oil content in Arabidopsis seeds was higher than in "greenhouse" experiments.

The plants used for this study were overexpressed with PDAT gene under the $35 \mathrm{~S}$ promoter, so one can argue that using a strong seed specific promoter would change the situation and cause an increase in seed oil content. Therefore, such experiment was also performed. The Arabidopsis plants were transformed with PDAT gene under napin promoter, so PDAT was expressed only in the seeds. However, also in this case the results were similar to those discussed above (data not presented).

The Arabidopsis plants used in the presented study are, however, probably not the best plants for studying PDAT overexpression on oil content in seeds. The Zhang et al. (2009) showed that DGAT and PDAT have overlapping functions in Arabidopsis triacylglycerol biosynthesis. Thus, one can speculate that PDAT overexpression causes a decrease in DGAT activity, and the final results of activity of both enzymes remains the same as in control plants. Experiments with other plants could bring completely different results, and satisfy the preliminary expectation that overexpression of PDAT can increase the seed oil content, as was initially observed in case of yeast cells (Dahlqvist et al., 2000) or recently in leaves of Arabidopsis plants (Fan et al., 2013a, 2013b).

\section{Acknowledgements}

The research was partially supported by BASF. The authors would also like to thank Professor Sten Stymne from the Swedish University of Agricultural Sciences for his comprehensive help throughout this research. Publication was supported by the European Commission from the EP7 project "MOBI4Health".

\section{References}

Banaś, A., Dahlqvist, A., Ståhl, U., Lenman, M., \& Stymne, S. (2000). The involvement of phospholipid: diacylglycerol acyltransferases in triacylglycerol production. Biochem. Soc. Trans, 28, 703-705. http:dx.doi.org/10.1042/0300-5127:0280703

Banaś, W., Garcia, A. S., Banaś, A., \& Stymne, S. (2013). Activities of acyl-CoA: diacylglycerol acyltransferase (DGAT) and phospholipid: diacylglycerol acyltransferase (PDAT) in microsomal preparations of developing sunflower and safflower seeds. Planta, 237(6), 1627-1636. http:dx.doi.org/10.1007/s00425-013-1870-8

Bligh, E. G., Dyer, W. J. (1959). A rapid method of total lipid extraction and purification. Can. J. Med. Sci., 37, 911-917. http:dx.doi.org/10.1139/o59-099

Bouvier-Nave, P., Benvenise, P., Oelkers, P., Sturley, S., \& Schaller, H. (2000). Expression in yeast and tobacco of plant cDNAs encoding acyl-CoA: diacylglycerol acyltransferase. Eur. J. Biochem, 267, 85-96. http:dx.doi.org/10.1046/j.1432-1327.2000.00961.x

Cases, S., Smith, S. J., Zheng, Y. W., Myers, H. M., Lear, S. R., Sande, E., \& Farese, R. V. (1998). Identification of a gene encoding an acyl CoA: diacylglycerol acyltransferase, a key enzyme in triacylglycerol synthesis. Proceedings of the National Academy of Sciences, 95(22), 13018-13023. http:dx.doi.org/10.1073/pnas.95.22.13018 
Chapman, K. D., Dyer, J. M., \& Mullen, R.T. (2012). Biogenesis and functions of lipid droplets in plants: thematic review series: lipid droplet synthesis and metabolism: from yeast to man. J. Lipid Res., 53, 215-226. http:dx.doi.org/10.1194/jlr.R021436

Dahlqvist, A., Ståhl, U., Lenman, M., Banas, A., Lee, M., Sandager, L., ... \& Stymne, S. (2000). Phospholipid: diacylglycerol acyltransferase: an enzyme that catalyzes the acyl-CoA-independent formation of triacylglycerol in yeast and plants. Proceedings of the National Academy of Sciences, 97(12), 6487-6492. http:dx.doi.org/10.1073/pnas.120067297

Fan, J., Yan, C., \& Xu, C. (2013a). Phospholipid: diacylglycerol acyltransferase-mediated triacylglycerol biosynthesis is crucial for protection against fatty acid-induced cell death in growing tissues of Arabidopsis. Plant J., 76(6), 930-942. http:dx.doi.org/10.1111/tpj.12343

Fan, J., Yan, C., Zhang, X., \& Xu, C. (2013b). Dual role for phospholipid: diacylglycerol acyltransferase: enhancing fatty acid synthesis and diverting fatty acids from membrane lipids to triacylglycerol in Arabidopsis leaves. Plant Cell, 25(9), 3506-3518. http:dx.doi.org/10.1105/tpc.113.117358

Głąb, B., Furmanek, T., Miklaszewska, M., Banaś, A., \& Królicka, A. (2013). Lipids in hairy roots and non-Agrobacterium induced roots of Crambe abyssinica. Acta Physiol. Plant, 35, 2137-2145. http:dx.doi.org/10.1007/s11738-013-1250-9

Hernandez, M. L., Whitehead, L., He, Z., Gazda, V., Gilday, A., Kozhevnikowa, E., ... Graham, I. A. (2012). A cytosolic acyltransferase contributes to triacylglycerol synthesis in sucrose-rescued Arabidopsis seed oil catabolism mutants. Plant Physiol., 160, 215-225. http:dx.doi.org/10.1104/pp.112.201541

Hobbs, D. H., Lu, C., \& Hills, M. J. (1999). Cloning of a cDNA encoding diacylglycerol acyltransferase from Arabidopsis thaliana and its functional expression. FEBS letters, 452(3), 145-149. http://dx.doi.org/10.1016/S0014-5793(99)00646-8

Huang, A. H. C. (1996). Oleosins and oil bodies in seeds and other organs. Plant Physiol., 110, 1055-1061. http://dx.doi.org/10.1104/pp.110.4.1055

Jako, C., Kumar, A., Wei, Y., Zou, J., Barton, D. L., Giblin, E. M., ... Taylor, D. C. (2001). Seed-specific over-expression of an Arabidopsis cDNA encoding a diacylglycerol acyltransferase enhances seed oil content and seed weight. Plant Physiol., 126, 861-874. http://dx.doi.org/10.1104/pp.126.2.861

Kelly, A. A., van Erp, H., Quettler, A. L., Shaw, E., Menard, G., Krup, S., \& Eastmond, P. J. (2013). The sugar-dependent1 lipase limits triacylglycerol accumulation in vegetative tissues of Arabidopsis. Plant Physiol., 162, 1282-1289. http://dx.doi.org/10.1104/pp.113.219840

Kennedy, E. P. (1961). Biosynthesis of complex lipids. Fed. Proc. Fed. Am. Soc. Exp. Biol., 20, 934-940.

Kroon, J. T. M., Wei, W. X., Simon, W. J., \& Slabas, A. R. (2006). Identification and functional expression of type 2 acyl-CoA:diacylglycerol acyltransferase (DGAT2) in developing castor bean seeds which has high homology to the major triglyceride biosynthetic enzyme of fungi and animals. Phytochemistry, 67, 2541-2549. http://dx.doi.org/10.1016/j.phytochem.2006.09.020

Lardizabal, K. D., Mai, J. T., Wagner, N. W., Wyrick, A., Voelker, T., \& Hawkins, D. J. (2001). DGAT2 is a new diacylglycerol acyltransferase gene family - purification, cloning, and expression in insect cells of two polypeptides from Mortiella ramaniana with diacylglycerol acyltransferases activity. J. Biol. Chem., 276, 38862-38869. http:dx.doi.org/10.1074/jbc.M106168200

Liu, Q., Siloto, R. M., Lehner, R., Stone, S. J., \& Weselake, R. J. (2012). Acyl-CoA:diacylglycerol acyltransferase: molecular biology, biochemistry and biotechnology. Prog. Lipid Res., 51, 350-377. http:dx.doi.org/10.1016/j.plipres.2012.06.001

Oelkers, P., Tinkelenberg, A., Erdeniz, N., Cromley, D., Billheimer, J. T., \& Sturley, S. L. (2000). A lecithin cholesterol acyltransferase-like gene mediates diacylglycerol esterification in yeast. J. Bioch. Chem., 275, 15609-15612. http:dx.doi.org/10.1074/jbc.C000144200

Ohlrogge, J. B., \& Browse, J. (1995). Lipid biosynthesis. Plant Cell, 7, 957-970. http:dx.doi.org/http://dx.doi.org/10.1105/tpc.7.7.957

Perry, H. Y., \& Harwood, J. L. (1993a). Changes in the lipid content of developing seeds of Brassica napus. Phytochemistry, 32, 1411-1415. http://dx.doi.org/10.1016/0031-9422(93)85148-K 
Perry, H. Y., \& Harwood, J. L. (1993b). Use of [2- $\left.{ }^{3} \mathrm{H}\right]$ glycerol precursor in radiolabelling studies of acyl lipids in $\begin{array}{lllll}\text { developing seeds of Brassica napus. Phytochemistry, } & \text { 34, }\end{array}$ http://dx.doi.org/10.1016/S0031-9422(00)90784-2

Perry, H. Y., Bligny, R., Gount, E., \& Harwood, J. L. (1999). Changes in Kennedy pathway intermediates associated with increased triacylglycerol synthesis in oil-seeds rape. Phytochemistry, 52, 799-804. http://dx.doi.org/10.1016/S0031-9422(99)00294-0

Saha, S., Enugutti, B., Rajakumari, S., \& Rajasekharan, R. (2006). Cytosolic triacylglycerol biosynthetic pathway in oilseeds: molecular cloning and expression of peanut cytosolic diacylglycerol acyltransferase. Plant Physiol., 141, 1533-1543. http:dx.doi.org/10.1104/pp.106.082198

Settlage, S. H., Wilson, R. F., \& Kwanyuen, P. (1995). Localization of diacylglycerol acyltransferase to oil body associated endoplasmic reticulum. Plant Physiol Biochem, 33, 399-407.

Shockey, J. M., Gidda, S. K., Chapital, D. C., Kuan. J. C., Dhanoa, P. K., Bland, J. M., .. Dyer, J. M. (2006). Tung tree GDAT1 and DGAT2 have non redundant functions in triacylglycerol biosynthesis and are localized to different subdomains of the endoplasmic reticulum. Plant Cell, 18, 2294-2313. http://dx.doi.org/10.1105/tpc.106.043695

Ståhl, U., Carlsson, A., Lenman, M., Dahlqvist, A., Huang, B., Banaś, W., ... Stymne, S. (2004). Cloning and functional characterization of a phospholipid : diacylglycerol acyltransferase from Arabidopsis. Plant Physiol., 135, 1324-1335. http://dx.doi.org/10.1104/pp.104.044354

Stobart, A. K., \& Stymne, S. (1985). The regulation of fatty acid composition of the triacylglycerols in microsomal preparation from avocado mesocarp and developing cotyledons of safflower. Planta, 163, 119-125. http:dx.doi.org/10.1007/BF00395905

Stymne, S. T. E. N., \& Stobart, A. K. (1987). Triacylglycerol biosynthesis. Biochemistry of plants, 9, 175-214.

Vanhercke, T., El Tahchy, A., Liu, Q., Zhou, X. R., Shrestha, P., Divi, U. K., \& Petrie, J. R. (2014). Metabolic engineering of biomass for high energy density: oilseed-like triacylglycerol yields from plant leaves. Plant Biotechnol. J., 12(2), 231-239. http:dx.doi.org/10.1111/pbi.12131

Zhang, M., Fan, J., Taylor, D., \& Ohlrogge, J. (2009). DGAT1 and PDAT1 acyltransferases have overlapping functions in Arabidopsis triacylglycerol biosynthesis and are essential for normal pollen and seed development. Plant Cell., 21(12), 3885-3901. http:dx.doi.org/10.1105/tpc.109.071795

Zou, J., Wei, Y., Jako, C., Kumar, A., Selvaraj, G., \& Taylor, D. C. (1999). The Arabidopsis thaliana TAG1 mutant has a mutation in a diacylglycerol acyltransferase gene. Plant J., 19, 645-653. http:dx.doi.org/10.1046/j.1365-313x.1999.00555.x 


\section{Appendix}

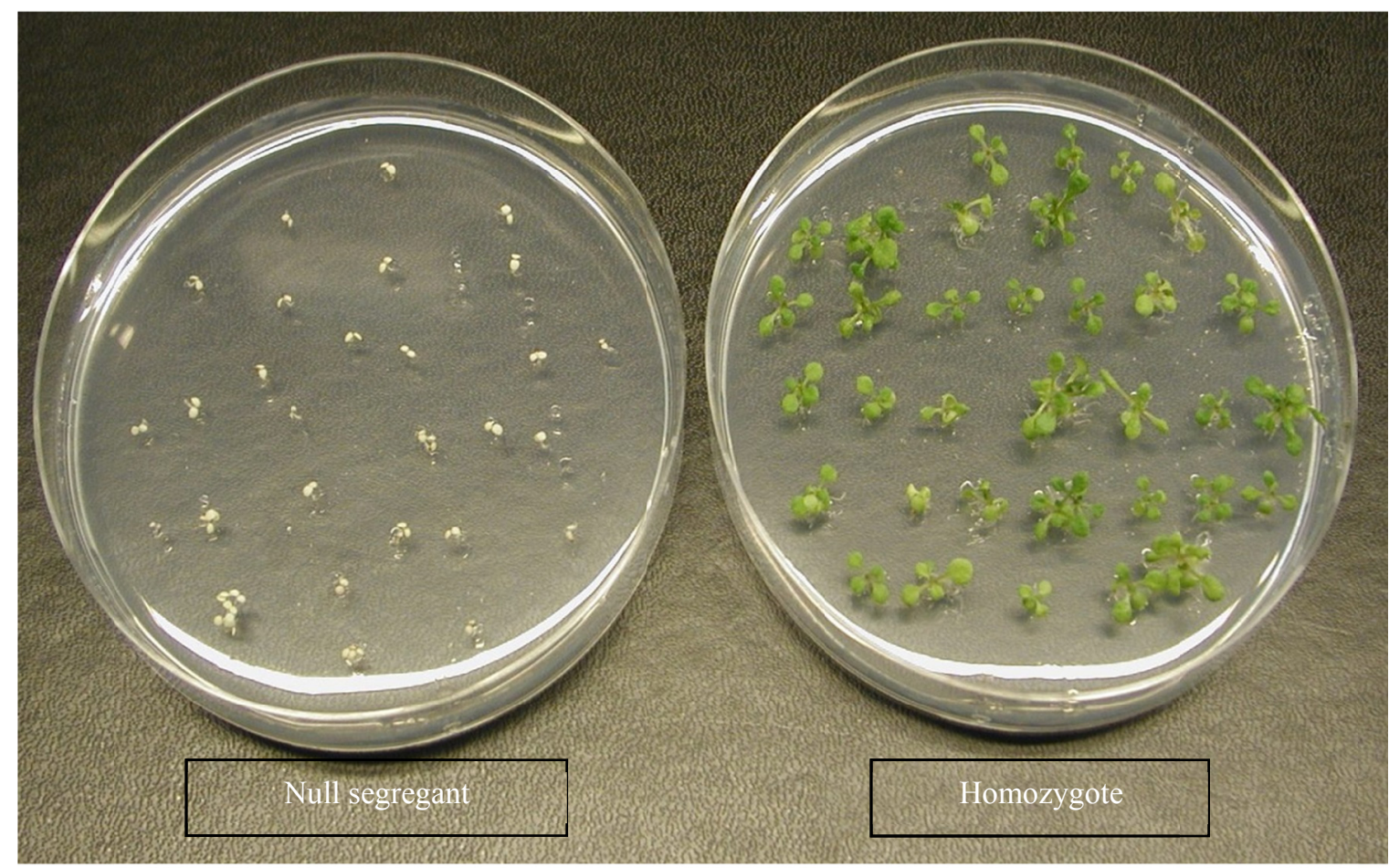

Photo S1. Selection of "null segregants" and homozygotes

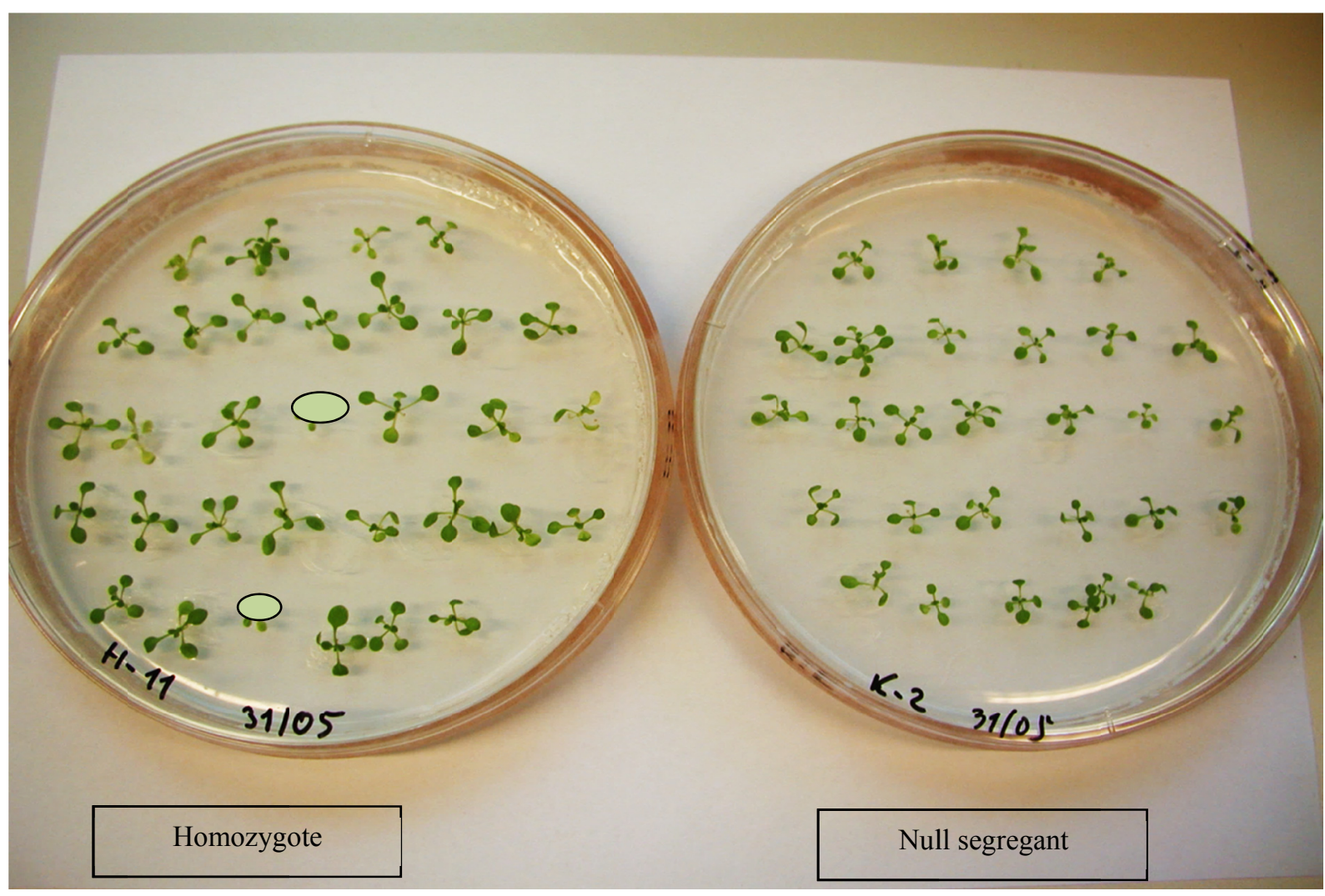

Photo S2. Evaluation of PDAT overexpression on Arabidopsis growth rate. 


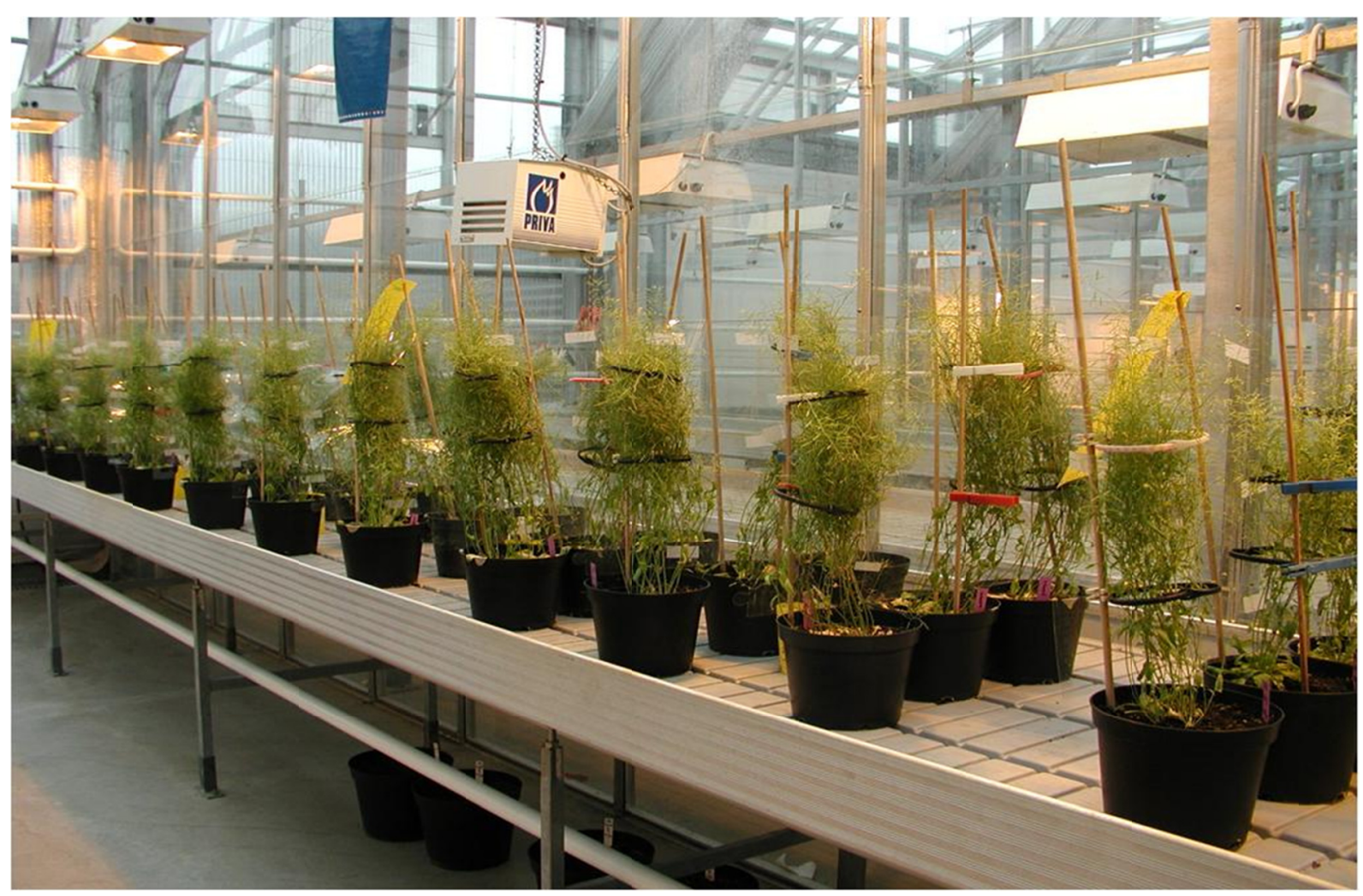

Photo S3. Greenhouse experiment.

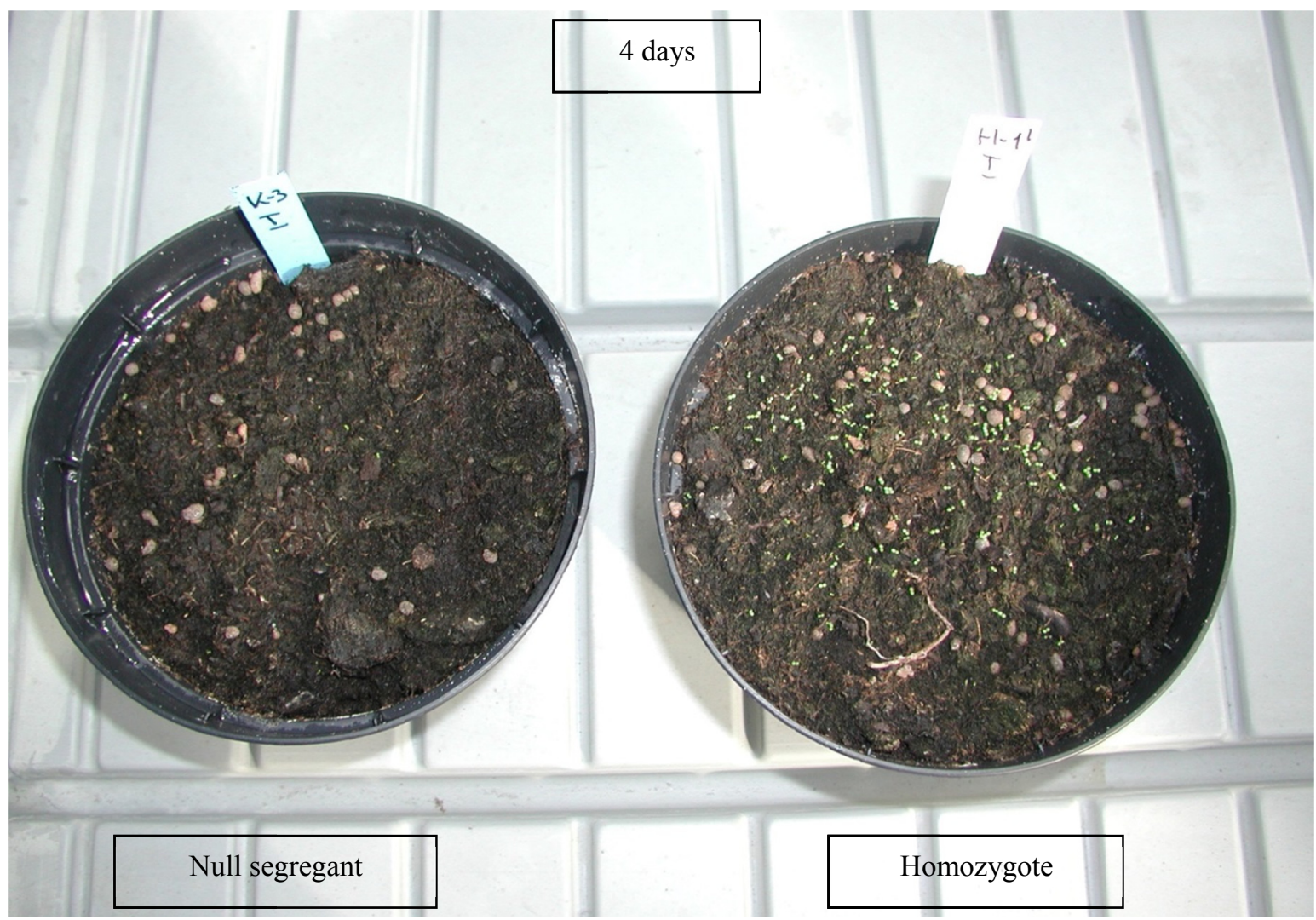

Photo S4. Effect of PDAT overexpression on germination of Arabidopsis seeds 


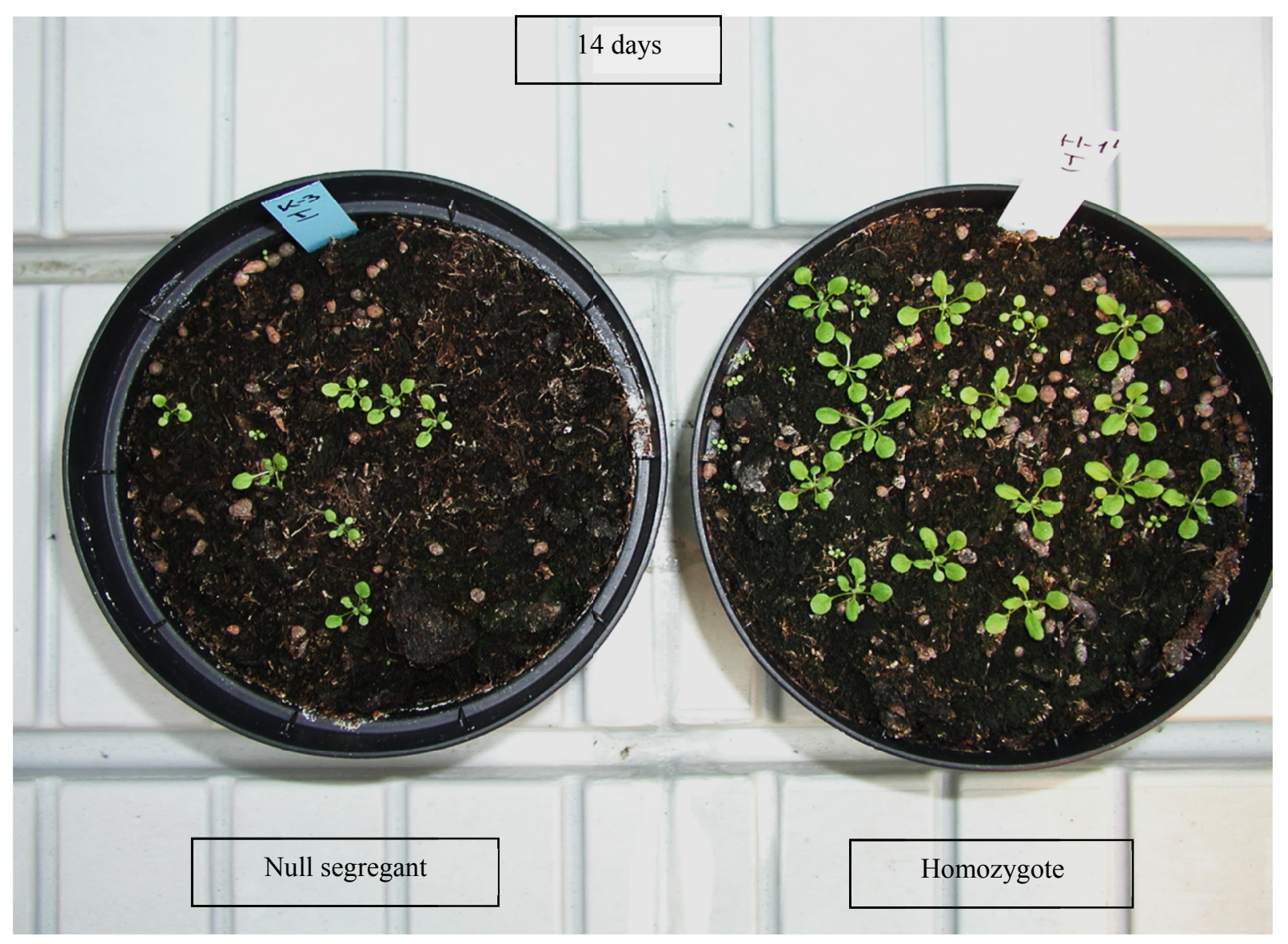

Photo S5. Effect of PDAT overexpression on growth rate of Arabidopsis seedlings 


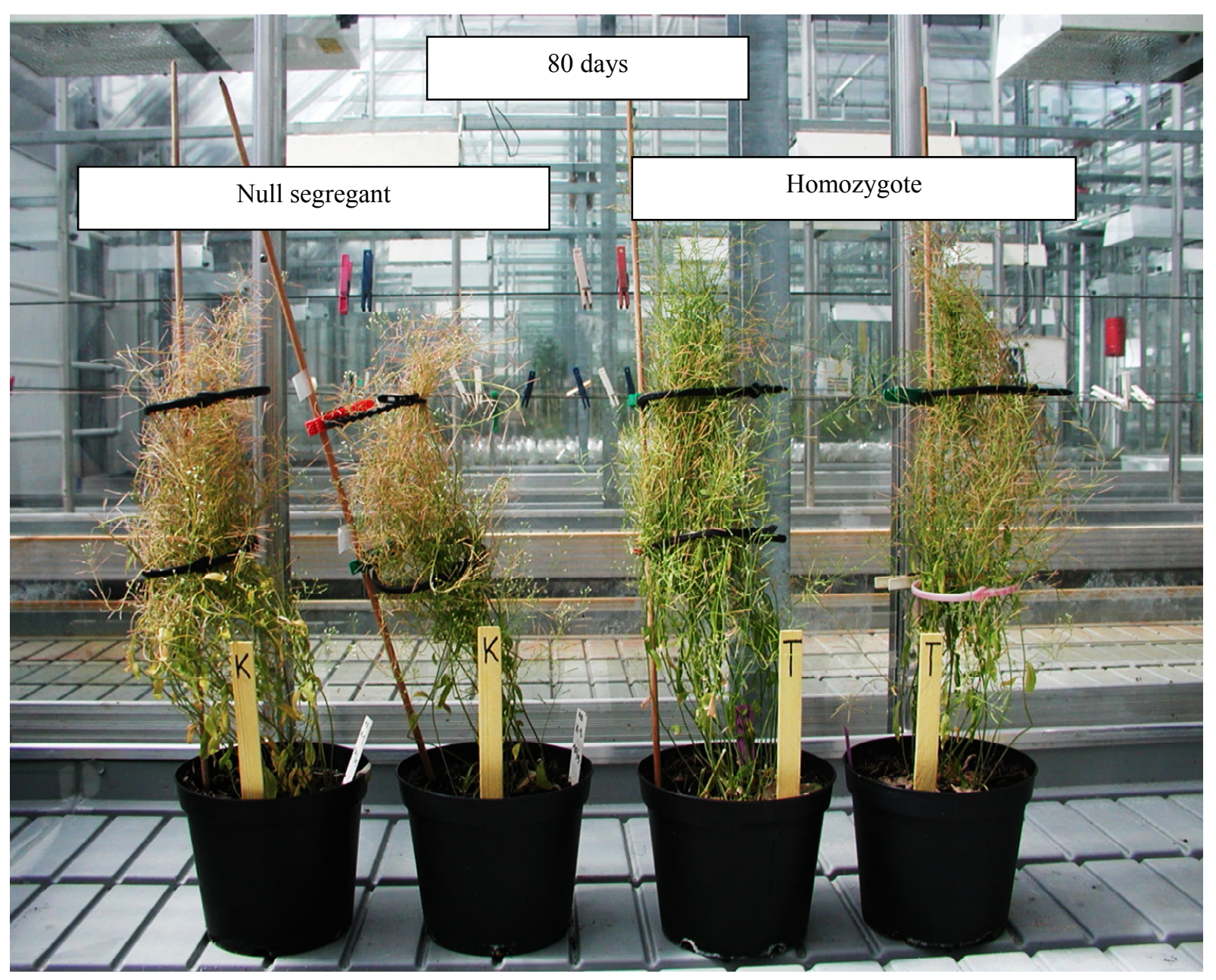

Photo S6. Effect of PDAT overexpression on growth rate of Arabidopsis plants

\section{Copyrights}

Copyright for this article is retained by the author(s), with first publication rights granted to the journal.

This is an open-access article distributed under the terms and conditions of the Creative Commons Attribution license (http://creativecommons.org/licenses/by/3.0/). 